\title{
Evaluation of the Role of Methional, 2-Keto-4-methylthiobutyric Acid and Peroxidase in Ethylene Formation by Escherichia coli
}

\author{
By S. B. PRIMROSE \\ Department of Biological Sciences, University of Warwick, \\ Coventry $\mathrm{CV}_{4} 7 \mathrm{AL}$
}

(Received 9 July 1976; revised 29 September 1976)

\begin{abstract}
SUMMARY
During growth of Escherichia coli strain SPA o in the presence of methionine, an intermediate accumulates in the medium. This intermediate reacts with 2,4-dinitrophenylhydrazine, and can be degraded to ethylene either enzymically or photochemically, the latter being stimulated by the addition of a flavin. The $\mathrm{pH}$ optimum for the photochemical degradation of this intermediate and 2-keto-4-methylthiobutyric acid (KMBA) is $\mathrm{pH} 3$ whereas the optimum for methional is $\mathrm{pH}$. The enzyme which converts the intermediate to ethylene also converts KMBA to ethylene and has many of the properties of a peroxidase including inhibition by catalase, cyanide, azide and anaerobiosis. The enzyme which synthesizes the intermediate is not known but requires oxygen and pyridoxal phosphate. A pathway for ethylene biosynthesis is proposed in which methionine is converted to KMBA which can be degraded either by peroxidase or in a flavin-mediated photochemical reaction. Its relevance to the properties of other ethylene-producing bacteria and to the proposed pathway of ethylene release by higher plants is discussed.
\end{abstract}

\section{INTRODUCTION}

There appear to be two routes of ethylene biosynthesis. In higher plants, the fungi Mucor hiemalis, Candida vartiovaariai and Trichosporon cutaneum and all bacteria, methionine is the precursor of ethylene (Yang, 1974; Lynch, 1972; Primrose \& Dilworth, 1976; Primrose, $1976 b$ ). In Penicillium digitatum the precursor of ethylene is $\alpha$-ketoglutarate or glutamate (Chou \& Yang, 1973) but other penicillia produce ethylene only in the presence of methionine (unpublished observations). There is confusion concerning the enzymes and intermediates involved in the conversion of methionine to ethylene by higher plants, and no information is available about the bacterial pathway.

Enzymic systems for conversion of methionine analogues to ethylene were first reported by Mapson \& Wardale (1967) and $\mathrm{Ku}$, Yang \& Pratt (1967). Both systems produced ethylene from methional (3-methylthiopropionaldehyde) but not from methionine, and required enzyme and cofactor fractions. These enzyme systems resembled peroxidase in many aspects and Yang ( 1967 ) subsequently showed that horseradish peroxidase catalysed the conversion of either methional or 2-keto-4-methylthiobutyric acid (KMBA; 2-oxomethionine) to ethylene. Baur \& Yang (I969) found that methional was not converted to ethylene in apple tissues, and although KMBA was readily converted to ethylene, the efficiency of its conversion was less than that from methionine (Baur \& Yang, I969). It was concluded that KMBA is not an intermediate in the conversion of methionine to ethylene. 
Mapson, March \& Wardale (I969) reported that KMBA stimulated ethylene production in cauliflower floret tissue, but this was later shown by Lieberman \& Kunishi (I97I) to be due to leakage of peroxidase from the tissue which reacted with the KMBA in the buffer solution surrounding the tissue.

The peroxidase-catalysed ethylene production differs from the pathway in vivo in a number of respects (Yang, I974). The peroxidase system utilizes methional and KMBA, but not methionine, whereas in intact tissue methionine is a more efficient precursor than methional. It is also known that monophenols promote ethylene production and that $o$-diphenols are inhibitors of the peroxidase system (Yang, 1967; Mapson, Self \& Wardale, 1969), whereas ethylene production from intact tissue is not greatly influenced by the addition of either class of phenolic compounds (Gahagan, Holm \& Abeles, 1968). Catalase is also known to be a potent inhibitor of the peroxidase system but it failed to inhibit production of ethylene by cauliflower tissue (Lieberman \& Kunishi, 197I). Yang (1974) concluded that the available results fail to support the proposal that KMBA, methional and peroxidase are involved in ethylene biosynthesis in vivo. However, Lynch (1974) and Primrose (1976a) presented evidence suggesting that $M$. hiemalis and Escherichia coli, growing in the presence of methionine, accumulate intermediates which can be photochemically degraded to ethylene, a property of KMBA and methional (Yang, Ku \& Pratt, 1967; Ku \& Leopold, 1970). Furthermore, Primrose (1976 $b$ ) noted an inverse correlation between the catalase activity of an organism and its ability to produce ethylene, suggesting that peroxidase is involved in the biosynthesis of ethylene. Here, evidence for the involvement of KMBA and peroxidase in ethylene production is presented.

\section{METHODS}

Organism, culture medium and buffer. Escherichia coli SPA O and Pseudomonas isolates BI2A, BI7E and BI6в have been described previously (Primrose, I976a,b). The defined medium of Brown \& Dilworth (1975) was used; nitrogen was added as ammonium acetate $\left(275 \mathrm{mg} \mathrm{l}^{-1}\right)$ and carbon as glucose $\left(4^{\circ} \circ \mathrm{g}^{-1}\right)$. When required, methionine, KMBA (Sigma) and riboflavin were added to give concentrations of $500 \mathrm{mg} \mathrm{l}^{-1}, 200 \mathrm{mg} \mathrm{l}^{-1}$ and $\mathrm{Io} \mathrm{mg} \mathrm{l}^{-1}$ respectively. The inhibitors, chloramphenicol and L-canaline (Sigma), were used at concentrations of $100 \mathrm{mg} \mathrm{l}^{-1}$ and $50 \mathrm{mg} \mathrm{l}^{-1}$ respectively. Catalase (Sigma) was added at various concentrations when required.

GMP buffer contained $\left(\mathrm{g} \mathrm{l}^{-1}\right): \mathrm{K}_{2} \mathrm{HPO}_{4}, \mathrm{I} \cdot 4 ; \mathrm{KH}_{2} \mathrm{PO}_{4}, 0 \cdot 36$; glucose, 4; and methionine, 0.5 . The $\mathrm{pH}$ was adjusted to 5.5 .

Growth in sealed flasks. Liquid cultures were grown in $250 \mathrm{ml}$ conical flasks with groundglass necks and were fitted with standard turnover-type rubber bungs (Suba-Seal; Wm Freeman, Barnsley, Yorkshire). The bungs were sterilized in alcohol to avoid ethylene release. When the cellular formation of ethylene was being studied, light was excluded by wrapping the flasks in heavy-duty aluminium foil before incubation. For studies of photochemical production of ethylene, illumination was provided by a $100 \mathrm{~W}$ tungsten bulb placed at a distance of $30 \mathrm{~cm}$ (approximately $4 \mathrm{klux}$ ). When anaerobic conditions were required, the flasks were gassed for about $10 \mathrm{~min}$ with oxygen-free nitrogen.

Culture filtrates were obtained by centrifuging samples of the culture $(20 \mathrm{ml})$ to remove the cells, and the resulting supernatant fluid was sterilized by filtration.

Assay of ethylene. Gas samples ( $\mathrm{I} \mathrm{ml}$ ) were withdrawn from the sealed flasks and analysed using a Pye Unicam Series I04 chromatograph with a flame ionization detector, a $\mathrm{I} \cdot 6 \mathrm{~m} \times$ $6 \mathrm{~mm}$ column of Porapak $\mathrm{R}$ at $85^{\circ} \mathrm{C}$, and a nitrogen carrier gas flow of $40 \mathrm{ml} \mathrm{min}{ }^{-1}$. 
2,4-Dinitrophenylhydrazone preparation. One $\mathrm{ml} \quad 0 \cdot \mathrm{I} \% \quad 2,4$-dinitrophenylhydrazine in $2 \mathrm{M}-\mathrm{HCl}$ was added to $20 \mathrm{ml}$ cell-free filtrate and stirred at room temperature for $20 \mathrm{~min}$.

Metal ions. For experiments on the effect of metal ions on ethylene production by washed cells, $\mathrm{Fe}^{3+}, \mathrm{Ca}^{2+}$ and $\mathrm{Mg}^{2+}$ were supplied at the concentrations normally present in the growth medium. For experiments on the effect of manganese and sulphite ions on ethylene production by culture filtrates, I $\mathrm{ml} \mathrm{MnCl}_{2}$ ( I mM), sodium sulphite (0.04 M), KMBA $(0.02 \mathrm{M})$ or methional $(0.02 \mathrm{M}$; Sigma) was added to $20 \mathrm{ml}$ filtrate $(\mathrm{pH} 5.5)$ in a $250 \mathrm{ml}$ conical flask and incubated at $30^{\circ} \mathrm{C}$ in the dark.

\section{RESULTS}

\section{Evidence for an intermediate in ethylene biosynthesis}

Filtrates from cultures grown in the presence of methionine released ethylene on illumination, whereas addition of methionine to filtrates from control cultures grown in the absence of methionine did not produce ethylene (Fig. I). This result shows that an intermediate in ethylene biosynthesis accumulates in the growth medium of cells grown in the presence of methionine. Addition of KMBA, a potential precursor of ethylene, to filtrates from cultures grown in the presence of methionine had relatively little effect, but its addition to filtrates from control cultures resulted in ethylene formation. This observation suggests that a cofactor necessary for degradation of the precursor to ethylene is limiting in these filtrates, resulting in accumulation of the precursor. Since light stimulates the formation of ethylene (Primrose, 1976a) and many of the best ethylene-producing bacteria secrete flavin-like pigments (Primrose, I $976 b$ ), a flavin may be the necessary cofactor. When riboflavin and methionine were added to filtrates of cultures grown in the absence of methionine, only slow release of ethylene occurred. By contrast, addition of riboflavin to filtrates of cultures grown in the presence of methionine resulted in a 30-fold stimulation of ethylene production (Fig. 2). Higher concentrations of riboflavin gave proportional increases in the rates of ethylene production, indicating the presence of a high concentration of precursor. Cell-free filtrates from cultures of the ethylene-producing isolates BI2A, BI7E and B 16B (Primrose, I $976 b$ ), which secrete flavin-like pigments, were able to replace riboflavin in stimulating ethylene formation.

Addition of 2,4-dinitrophenylhydrazine to filtrates of cultures grown in the presence of methionine resulted in the formation of an orange precipitate characteristic of the 2,4dinitrophenylhydrazone derivative of an aldehyde or ketone. Chemical characterization of the precipitate suggested that it was the 2,4-dinitrophenylhydrazone derivative of KMBA (Primrose \& Golding, unpublished observations). Precipitate formation could be prevented by first adding riboflavin and illuminating until no further ethylene was released. As expected, no precipitate formed when methionine and 2,4-dinitrophenylhydrazine were added to filtrates of control cultures grown in the absence of methionine.

\section{Effect of chloramphenicol on induction of ethylene biosynthesis}

Ethylene formation by cells in the dark was induced by methionine but this could be inhibited by adding chloramphenicol with the methionine (Fig. 3). However, the conversion of KMBA to ethylene by cells in the dark was unaffected by chloramphenicol (Fig. 3) sugge sting that this conversion is mediated by a pre-existing enzyme. 


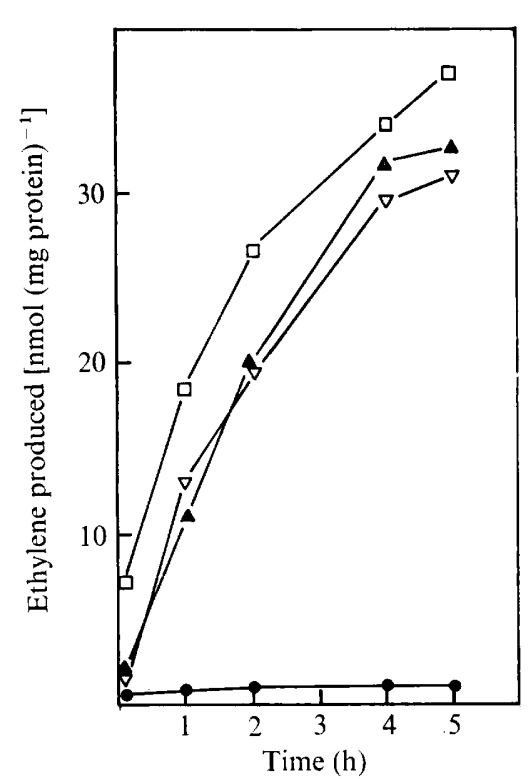

Fig. I

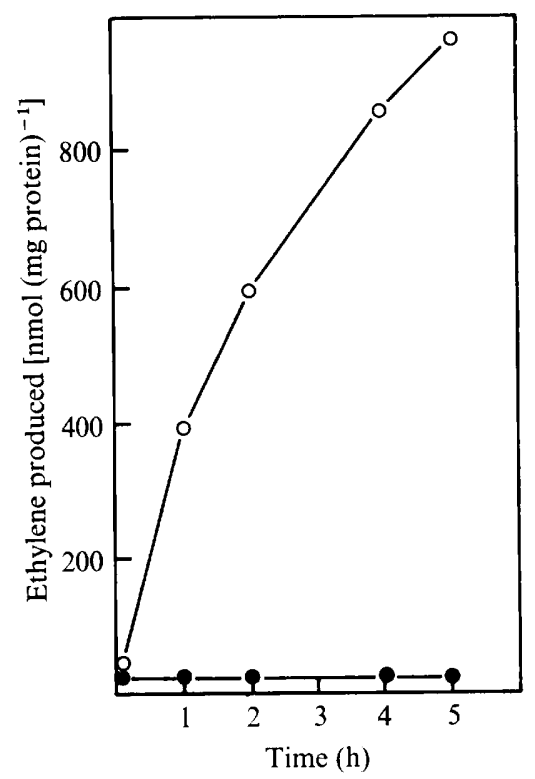

Fig. 2

Fig. I. Photochemical production of ethylene by culture filtrates of E. coli. Cells were either grown in the presence of $500 \mu \mathrm{g}$ methionine $\mathrm{ml}^{-1}(\square, \boldsymbol{\Delta})$ or in its absence $(\nabla,-\Theta)$, and KMBA $(\square, \nabla)$ or methionine (O) was added to the culture filtrates.

Fig. 2. Effect of riboflavin on the photochemical production of ethylene from culture filtrates of $E$. coli. $\bigcirc$, Riboflavin added to culture filtrates prepared from cells grown in the presence of methionine; , riboflavin and methionine added to culture filtrates from cells grown in the absence of methionine. Note the scale of the ordinate compared with Fig. I.

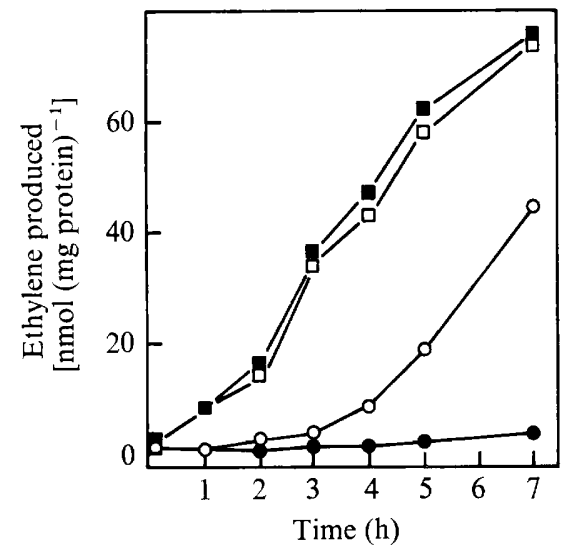

Fig. 3

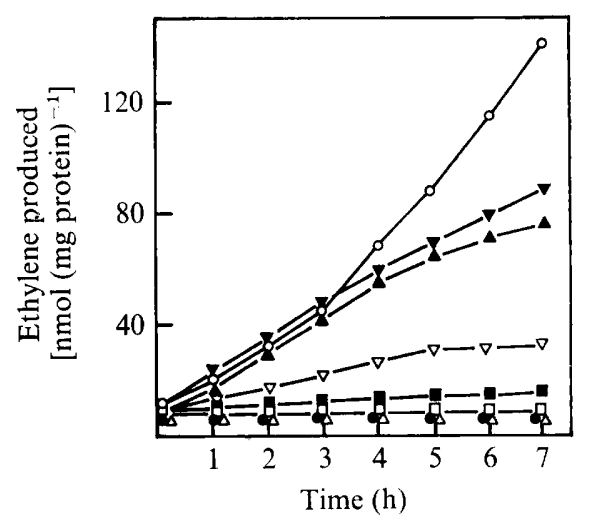

Fig. 4

Fig. 3. Effect of chloramphenicol on the production of ethylene from KMBA and methionine by $E$. coli in the dark. Cells were grown in the absence of methionine and the following additions made: methionine (O), methionine plus chloramphenicol (O), KMBA ( $\boldsymbol{0})$, KMBA plus chloramphenicol $(\square)$.

Fig. 4. Effect of metal ions on ethylene production by washed cells of $E$. coli. Cells grown in the presence of methionine were washed and resuspended in the supernatant fluid $(O)$ or in GMP buffer plus: $\mathrm{Mg}^{2+}(\mathbf{O}) ; \mathrm{Ca}^{2+}(\square) ; \mathrm{Fe}^{8+}(\square) ; \mathrm{Mg}^{2+}$ and $\mathrm{Ca}^{2+}(\triangle) ; \mathrm{Mg}^{2+}$ and $\mathrm{Fe}^{3+}(\boldsymbol{\Delta}) ; \mathrm{Ca}^{2+}$ and $\mathrm{Fe}^{3+}(\nabla) ; \mathrm{Mg}^{2+}, \mathrm{Ca}^{2+}$ and $\mathrm{Fe}^{3+}(\nabla)$. 


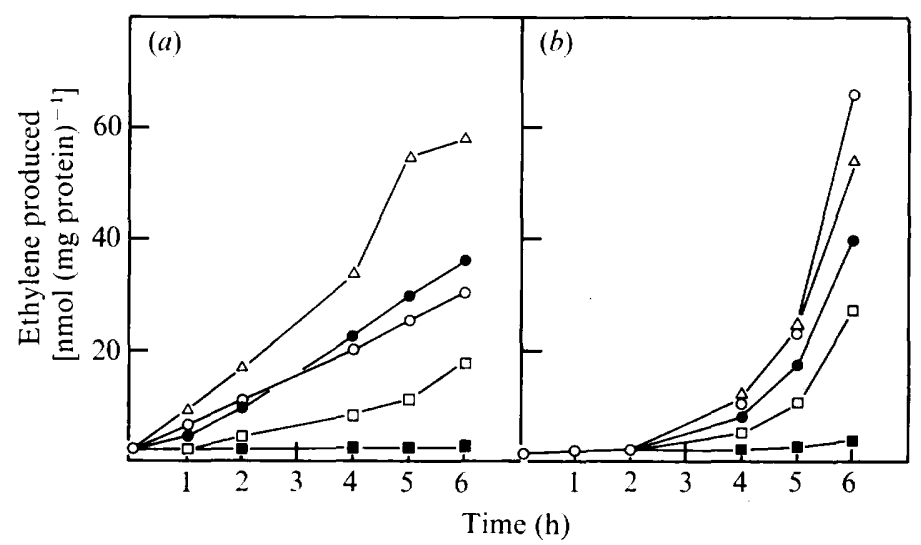

Fig. 5. Effect of catalase on the production of ethylene from KMBA and methionine by $E$. coli in the dark. Cells were grown in the absence of methionine, and $(a)$ KMBA or $(b)$ methionine was added simultaneously with the following concentrations of catalase: $\bigcirc$, none added; $0,10 \mu \mathrm{g} \mathrm{ml}^{-1}$; $\square, \mathrm{I} 00 \mu \mathrm{g} \mathrm{ml}^{-1} ; \mathbf{\square}, \mathrm{I} \mathrm{mg} \mathrm{ml}^{-1} ; \triangle, \mathrm{I} \mathrm{mg}$ boiled catalase $\mathrm{ml}^{-1}$.

\section{Effect of catalase on ethylene formation}

If peroxidase is involved in the cellular conversion of methionine to ethylene then ethylene biosynthesis should be inhibited by catalase. High concentrations of catalase inhibited the conversion of KMBA (Fig. $5 a$ ) and methionine (Fig. $5 b$ ) to ethylene in the dark by cells of E. coli. However, boiled catalase slightly stimulated ethylene formation.

\section{Cofactors required for the cellular formation of ethylene}

When ethylene-producing cells were washed and resuspended in fresh medium containing methionine, ethylene production recommenced after a short lag period providing protein synthesis was not inhibited. If the cells were resuspended in buffer containing glucose and methionine, rather than growth medium, ethylene formation did not recommence. By varying the composition of the growth medium, the failure of buffer solutions to permit ethylene formation was eventually traced to a requirement for $\mathrm{Fe}^{3+}, \mathrm{Mg}^{2+}$ and, to a lesser extent, $\mathrm{Ca}^{2+}$ ions (Fig. 4). Washed cells grown in the absence of methionine also failed to convert KMBA to ethylene if suspended in buffer lacking these cations.

Filtrates of cultures grown in the presence of methionine failed to produce ethylene when incubated in the dark (Primrose, 1976a). Ethylene formation could, however, be induced by addition of $\mathrm{Mn}^{2+}$ and sulphite (Table I). Filtrates from cultures grown in the absence of methionine generated ethylene only when KMBA was added with the $\mathrm{Mn}^{2+}$ and sulphite.

\section{Effect of $p H$ on ethylene formation}

The production of ethylene in the dark by cells growing in the presence of methionine had a pH optimum of 5.5 ; the same value was found for the conversion of KMBA to ethylene by cells grown in the dark without methionine. In contrast, photochemical production of ethylene by filtrates of cultures grown in the presence of methionine had an optimum of $\mathrm{pH} 3$, even with additional riboflavin. An optimum of $\mathrm{pH}_{3}$ was also found for the photochemical production of ethylene by mixtures of KMBA and riboflavin. When KMBA was replaced by methional, another potential precursor of ethylene (Yang, 1967; Yang, 1969), the $\mathrm{pH}$ optimum shifted to 6 . 
Table I. Effect of sulphite and manganese ions on ethylene production by culture filtrates (CF) of $E$. coli

\begin{tabular}{lc}
\multicolumn{1}{c}{ culture filtrates $(\mathrm{CF})$ of $E$. coli } & $\begin{array}{c}\text { Ethylene } \\
\text { produced } \\
\left(\mathrm{nmol} \mathrm{h}^{-1}\right)\end{array}$ \\
E. coli grown in the absence of methionine & 0 \\
$\mathrm{CF}$ & 0 \\
$\mathrm{CF}+\mathrm{Mn}^{2+}$ & 0 \\
$\mathrm{CF}+$ sulphite & 0 \\
$\mathrm{CF}+\mathrm{Mn}^{2+}+$ sulphite & 0 \\
$\mathrm{CF}+\mathrm{Mn}^{2+}+\mathrm{KMBA}$ & $9 \cdot 58$ \\
$\mathrm{CF}+$ sulphite $+\mathrm{KMBA}$ & $69 \cdot 40$ \\
$\mathrm{CF}+$ sulphite $+\mathrm{Mn}^{2+}+\mathrm{KMBA}$ & $3 \cdot 18$ \\
$\mathrm{Buffer}(\mathrm{pH} 5 \cdot 5)+\mathrm{Mn}^{2+}+$ sulphite $+\mathrm{KMBA}$ & \\
E. coli grown in the presence of methionine & 0 \\
CF & 0 \\
CF $+\mathrm{Mn}^{2+}$ & 0 \\
CF + sulphite & $267 \cdot 00$ \\
CF $+\mathrm{Mn}^{2+}+$ sulphite &
\end{tabular}

\section{Oxygen requirements for ethylene formation}

Cells of $E$. coli SPA o fail to convert methionine to ethylene under anaerobic conditions (Primrose, $1976 a$ ), although oxygen may only be necessary for part of the reaction sequence. It is required for the conversion of the precursor to ethylene (Primrose, 1976a) since cells which are producing ethylene, and consequently have accumulated the precursor, stop producing ethylene when the oxygen is replaced by nitrogen. Cells grown aerobically in the absence of methionine also fail to convert KMBA to ethylene under anaerobic conditions. To determine if oxygen is required for the biosynthesis of the intermediate, cells were grown aerobically and the oxygen was then removed before adding methionine. As expected, this culture failed to produce ethylene, unlike the aerobic control culture. Cell-free filtrates obtained from both cultures were then incubated aerobically in the presence of riboflavin and light. There was a rapid release of ethylene from the control cell-free filtrate but not from the filtrate prepared from the anaerobic culture, indicating that the intermediate did not accumulate in the absence of oxygen.

Primrose (1976a) reported that cell-free filtrates of cultures grown in the presence of methionine slowly released ethylene when incubated anaerobically in the light. The $\mathrm{pH}$ dependence of this photochemical reaction is illustrated in Fig. 6 and is compared with that of the riboflavin-mediated anaerobic conversion of KMBA to ethylene.

\section{Effect of inhibitors on ethylene formation}

Inhibition of the cellular conversion of methionine to ethylene was detected with I mMsodium azide and complete inhibition occurred at $10 \mathrm{mM}$. The inhibition curve obtained when azide was added to bacteria already producing ethylene was identical with that obtained when azide was added simultaneously with the methionine. Sodium azide also inhibited the conversion of KMBA to ethylene by bacteria grown in the absence of methionine, but higher concentrations were needed to achieve complete inhibition. Cyanide inhibited the conversion of methionine and KMBA to ethylene but, again, the shape of the two inhibition curves was slightly different. Cyanide at I mM completely inhibited the conversion of methionine to ethylene but the conversion of KMBA to ethylene was only $30 \%$ inhibited.

Murr \& Yang (1975) reported that L-canaline, a potent inhibitor of pyridoxal phosphatemediated reactions, inhibited the conversion of methionine to ethylene by apple tissue. Addition of $70 \mu \mathrm{M}-\mathrm{L}$-canaline resulted in $94 \%$ inhibition of the conversion of methionine to 


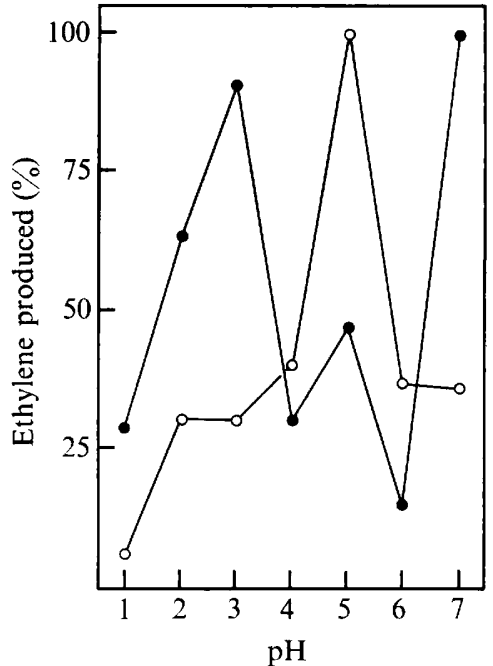

Fig. 6

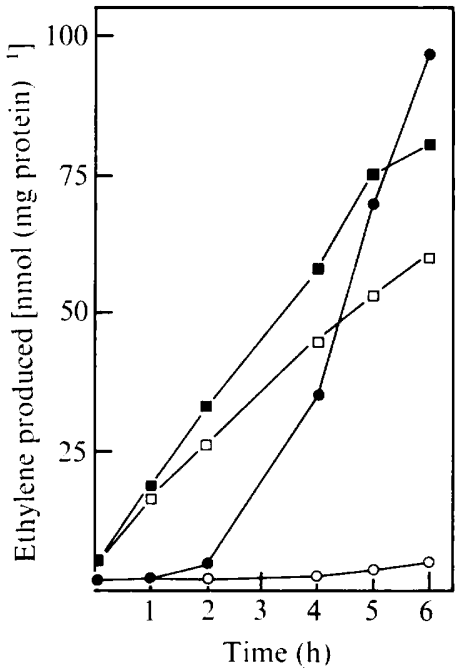

Fig. 7

Fig. 6. Effect of $\mathrm{pH}$ on the anaerobic formation of ethylene. Cell-free filtrates from cultures grown in the presence of methionine $(O)$ and KMBA (O) were incubated anaerobically in the light, and riboflavin was also present for the cells grown with KMBA. Ethylene production at the different $\mathrm{pH}$ values is expressed relative to the amount produced at the optimum $\mathrm{pH}$ value.

Fig. 7. Effect of L-canaline on the conversion of methionine and KMBA to ethylene by $E$. coli in the dark. Cells were grown in defined medium in the absence of methionine and KMBA and the following additions were made at o h: methionine (0); methionine plus L-canaline (O); KMBA ( $\square$ ); and KMBA plus L-canaline ( $\square$ ).

ethylene but only $20 \%$ inhibition of KMBA conversion (Fig. 7). The cellular conversion of precursor to ethylene was also relatively unaffected by the addition of L-canaline.

\section{DISCUSSION}

Primrose (1976a) suggested that $E$. coli SPA $O$ growing in the presence of methionine accumulates an intermediate in the pathway from methionine to ethylene. The data here confirm the existence of this precursor and show that its accumulation is partly due to the deficiency of a flavin. However, a low concentration of flavin must be secreted by all growing cultures of $E$. coli SPA o because filtrates from cultures grown in the absence of methionine still catalyse the photochemical degradation of KMBA.

As well as undergoing photochemical conversion, the ethylene precursor can be degraded enzymically (Primrose, 1976a). Yang (1967, 1969) has shown that peroxidase can catalyse the conversion of methional and KMBA to ethylene in vitro and the data here suggest that it is responsible for the conversion of the ethylene precursor in $E$. coli. Ethylene formation is prevented by catalase, azide and cyanide which are known inhibitors of peroxidase activity. Furthermore, the cells fail to generate ethylene from the precursor under anaerobic conditions (Primrose, 1976a) as would be expected if peroxidase were involved. Finally, its chloramphenicol insensitivity suggests that, like peroxidase, the enzyme must be constitutive, at least under aerobic conditions. The enzyme must be surface bound for it is readily lost when cells are washed (Fig. 4). Cell-free filtrates of cultures grown in the presence of methionine do not liberate ethylene when incubated in the dark (Primrose, I976a), indicating 
either that the enzyme loses its activity when free of the cells or that essential cofactors are missing. The latter alternative is supported by the stimulation of ethylene production by $\mathrm{Mn}^{2+}$ and sulphite. Yang (1967, I969) has shown that these two cofactors are essential for ethylene formation from KMBA and methional by horseradish peroxidase. Washed cells, regaining the ability to synthesize ethylene, require $\mathrm{Fe}^{3+}, \mathrm{Mg}^{2+}$ and, to a lesser extent, $\mathrm{Ca}^{2+}$. If peroxidase is the ethylene-generating enzyme in vivo then the need for $\mathrm{Fe}^{3+}$ is readily explicable. $\mathrm{Mg}^{2+}$ could be required for ribosome stability, but there is no apparent explanation for the slight stimulatory effect of $\mathrm{Ca}^{2+}$.

The intermediate in ethylene formation is either an aldehyde or a ketone for it reacts with 2,4-dinitrophenylhydrazine. Two derivatives of methionine which might serve this function are methional and KMBA, for both can be converted to ethylene either photochemically or enzymically by peroxidase (Yang, 1967; Yang, 1969; Yang et al., I967; Ku \& Leopold, 1970). The $\mathrm{pH}$ optimum for the photochemical degradation of methional is sufficiently different for it to be ruled out as the precursor. KMBA shares several properties with the precursor; the $\mathrm{pH}$ optima for the photochemical and enzymic conversions are similar and the enzymic conversion of both is inhibited by catalase, washing, azide and cyanide. However, KMBA and the precursor differ in their response to $\mathrm{pH}$ during the photochemical synthesis of ethylene under anaerobic conditions, and in the sensitivity of the enzymic conversion to inhibition by azide and cyanide.

At present, the identity of the enzyme forming the intermediate is unknown. If KMBA is the precursor then it could be produced by a transaminase. Although some transaminase activity would be constitutive, a catabolic methionine transaminase could be induced by methionine, like ethylene formation (Primrose, I976a; Figs 3, 4 and 7). An alternative enzyme would be L-amino acid oxidase but this enzyme has not been detected in $E$. coli strain SPA o (unpublished observations). Furthermore, synthesis of the intermediate is sensitive to $\mathrm{L}$-canaline inhibition, indicating a requirement for pyridoxal phosphate which is not a cofactor for L-amino acid oxidase. Wild et al. (1974) reported that D-amino acid dehydrogenase produces KMBA from D-methionine. This, or a similar enzyme, might also produce KMBA from L-methionine. It should be noted however, that Wild et al. (1974) observed that enzyme induction was poorest in glucose minimal medium and this is not true for ethylene production (Primrose, 1976a).

A pathway for ethylene biosynthesis can be elaborated (Fig. 8). Methionine is deaminated to KMBA which is then degraded to ethylene, either by peroxidase or photochemically in the presence of a flavin. L-Cysteine, L-homocysteine, L-formylmethionine, L-methionine methylester, L-methionine hydroxy analogue, L-ethionine and D-methionine also serve as substrates for ethylene formation (Primrose, I976a), but these, with the possible exception of the last two, would first be converted to methionine. Ethionine would probably be converted to 2-keto-4-ethylthiobutyric acid, and D-methionine may be converted to KMBA directly (Wild et al., 1974). Numerous groups of bacteria possess the ability to produce ethylene (Primrose, 1976b) but the amounts produced are frequently very small. Organisms which secrete low levels of flavins will exhibit little photochemical production of ethylene and if they possess significant catalase activity the action of peroxidase will be minimized. A satisfactory explanation is thus provided for the observation that the best ethylene producers either have low catalase activity or secrete flavin-like pigments (Primrose, 1976b).

The path of ethylene biosynthesis in E. coli strain SPA O differs from that proposed (Yang, 1974) for plant systems. Yang (1974) suggested that KMBA and peroxidase were not involved in ethylene production in plants because KMBA was a poorer substrate than 


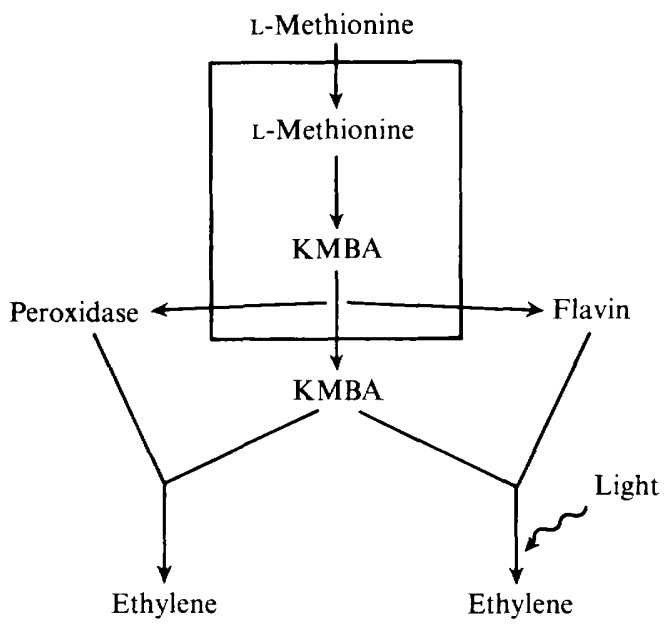

Fig. 8. Proposed scheme for the biosynthesis of ethylene.

methionine, and catalase failed to inhibit ethylene formation. However, KMBA may appear to be a poorer substrate because its rate of transport into intact plant cells is slower than methionine transport. Furthermore, catalase may fail to inhibit ethylene formation by plants because the peroxidase is not accessible to the catalase. Thus, the data on ethylene production by plant cells are not inconsistent with the pathway proposed for E. coli.

The author wishes to thank Mrs V. Waddell for her excellent technical assistance.

\section{REFERENCES}

Baur, A. H. \& YANG, S. F. (1969). Precursors of ethylene. Plant Physiology 44, I347-1 349.

Brown, C. M. \& Dilworth, M. J. (1975). Ammonia assimilation by Rhizobium cultures and bacteroids. Journal of General Microbiology 86, 39-48.

Chou, T. W. \& YAng, S. F. (1973). The biogenesis of ethylene in Penicillium digitatum. Archives of Biochemistry and Biophysics $\mathbf{1 5 7}, 73-82$.

Gahagan, H. E., Holm, R. E. \& Abeles, F. B. (1968). Effect of ethylene on peroxidase activity. Physiologia plantarum 2I, I 270-I 279.

Ku, M. S. \& LEOPOLD, A. C. (1970). Ethylene formation from peptides of methionine. Biochemical and Biophysical Research Communications 41, I I 55-I I60.

Ku, M.S., YANG, S. F. \& PratT, H. K. (1967). Enzymic evolution of ethylene from methional by a pea seedling extract. Archives of Biochemistry and Biophysics 118, 756-758.

Lieberman, M. \& Kunishi, A. T. (I97I). An evaluation of 4-S-methyl-2-keto-butyric acid as an intermediate in the biosynthesis of ethylene. Plant Physiology 47, 576-580.

LYNCH, J. M. (1972). Identification of substrates and isolation of micro-organisms responsible for ethylene production in the soil. Nature, London 240, 45-46.

LYNCH, J. M. (1974). Mode of ethylene formation by Mucor hiemalis. Journal of General Microbiology $\mathbf{8 3}$, 407-4II.

Marson, L. W. \& Wardale, D. A. (1967). Biosynthesis of ethylene. Formation of ethylene from methional by a cell-free enzyme system from cauliflower florets. Biochemical Journal ro2, 574-585.

Mapson, L. W., MARCh, J. F. \& WARDale, D. A. (1969). Biosynthesis of ethylene. 4-Methylthio-2-oxobutyric acid: an intermediate in the formation from methionine. Biochemical Journal Ir5, 653-66r.

Mapson, L. W., Self, R. \& Wardale, D. A. (1969). Biosynthesis of ethylene. Methanesulphonic acid as co-factor in the enzymic formation of ethylene from methional. Biochemical Journal rrI, 4I3-4I8.

MURR, D. P. \& YANG, S. F. (I975). Inhibition of in vivo conversion of methionine to ethylene by L-canaline and 2,4-dinitrophenol. Plant Physiology 55, 79-82. 
PrImrose, S. B. (I976a). Ethylene production by Escherichia coli SPA O. Journal of General Microbiology $95,159-165$.

PrimROSE, S. B. (1976b). Ethylene-forming bacteria from soil and water. Journal of General Microbiology 97 , $343-346$.

PrimRose, S. B. \& Dilworth, M. J. (I976). Ethylene production by bacteria. Journal of General Microbiology 93, $177-18 \mathrm{I}$.

YANG, S. F. (1967). Biosynthesis of ethylene: ethylene formation from methional by horseradish peroxidase. Archives of Biochemistry and Biophysics 122, 48I -487 .

YANG, S. F. (1969). Further studies on ethylene formation from 2-keto-4-methylthiobutyric acid or 3methylthiopropionaldehyde by peroxidase in the presence of sulfite or oxygen. Journal of Biological Chemistry 244, 4360-4365.

YANG, S. F. (1974). The biochemistry of ethylene: biogenesis and metabolism. In Recent Advances in Phytochemistry, vol. 7, pp. 13I-164. Edited by V. C. Runeckles, E. Sondheimer and D. C. Walton. New York: Academic Press.

YANG, S. F., Kv, M. S. \& Pratr, H. K. (1967). Photochemical production of ethylene from methionine and its analogues in the presence of flavin mononucleotide. Journal of Biological Chemistry 242, 5274-5280.

Wild, J., WALCZAK, W., KRAJEWSKA-GRYNKIEwICZ, K. \& KLOPOTOWSKI, T. (I974). D-Amino acid dehydrogenase: the enzyme of the first step of $\mathrm{D}$-histidine and $\mathrm{D}$-methionine racemization in Salmonella typhimurium. Molecular and General Genetics I28, I3I-I46. 